\title{
Smart Irrigation System using Cloud
}

\author{
Aishwarya Ghate \\ Department of Computer Engineering \\ New Horizon Institute of Technology and Management \\ Mumbai University \\ Thane, India \\ Rutuja Kamble \\ Department of Computer Engineering \\ New Horizon Institute of Technology and Management \\ Mumbai University \\ Thane, India
}

\begin{abstract}
As water gracefully is getting scant in this day and age there is a direness of embracing brilliant methods of water system. The undertaking portrays how water system can be taken care of keenly utilizing IOT. This venture targets sparing time and maintaining a strategic distance from issues like consistent cautiousness. It likewise helps in moderating water via naturally giving water to the plants/field contingent upon the water necessities. This framework can likewise end up being useful in horticulture, parks and gardens. The target of this framework is to distinguish the dampness substance of the dirt and relying upon it sprinkle water. This whole data will be sent to the client's cell phone.
\end{abstract}

Keywords:- Cloud, Arduino Uno, Wi-Fi Module, Microcontroller.

\section{INTRODUCTION}

Farming is one area which is totally subject to accessibility of new water. To utilize accessible restricted unadulterated/new water assets, not just that producers must need to have a proficient conveying technique for providing water to the plants, yet in addition an effective watering plan, so water is accessible to the plant at correct time with perfect measure of water. India's significant wellspring of salary is from horticulture area and $70 \%$ of ranchers and general individuals rely upon the agribusiness.

Indian water system framework that has been for the most part utilized are manual techniques, for example, trickle, terraced and sprinkle water system. So as to improve the yield efficiency there is a critical need to change manual strategy to computerization. Additionally, consider the water accessibility all through India it is one of the significant assets to secure and put something aside for the future needs. This paper features the working of the current innovations, for example, Arduino, Sensors, etc.

The entire framework is dispersed into two sections. The initial segment involves setting up an Arduino Board and interfacing it with the few sensors. The subsequent part

\author{
Sowmiya Rajagopal \\ Department of Computer Engineering \\ New Horizon Institute of Technology and Management \\ Mumbai University \\ Thane, India \\ Prof. Rushikesh Nikam \\ Department of Computer Engineering \\ New Horizon Institute of Technology and Management \\ Mumbai University \\ Thane, India
}

comprises of building up the IoT stage and interfacing it to the server. The ESP $8266 \mathrm{Wi}-\mathrm{Fi}$ module is utilized in view of which the transmission gets less difficult and quicker. It comprises of two engines one for water siphon, and second for manures siphon. In the wake of getting the best possible data about the field, rancher can turn ON/OFF the engines incidentally.

\section{LITERATURE SURVEY}

In this paper [1], System makes use of sensors which collects facts from the soil. The readings are compared with the threshold fee to determine the watering activity and watering is done primarily based on the situation of the rural land. The filter out is used to accumulate the water drained from the surface of the soil. The computerized recycling setup detects the water that's tired and uses suck motor to accumulate the water for in addition recycling. The recycled water receives saved in a storage reservoir which may be later used for irrigation purposes.

In this paper [3], Water control system is microcontroller based and internet utility the use of the idea of cloud and information mining's used to monitor and manage the water management machine from far flung location. Whole machine is in WSN infrastructure. Water management is done through sensor studying from farm. Web application provide easy reveal and manage mechanism to farmer. Graph generated in web software make easy analysis. Cloud computing is a way in which a big wide variety of computer systems connected via a realtime communique network.

In this paper [4], The esp module 8266 which is used to ship the statistics from an Arduino to IoT platform from which it could be accessed by way of the user. Wi-fi module incorporated with TCP/IP protocol and Has selfcontained SOC. ESP-8266 can easily offer wifi when it receives attached to an Arduino board because it has its own software meaning. Basically, it really works as a bridge between wireless and current microcontroller. 


\section{PROPOSED SYSTEM}

In this task, we order the Arduino microcontroller through a website page to run the engine (i.e., to begin and stop the engine) and the entire water system procedure will be naturally constrained by the microcontroller itself.

\section{$>$ Working:}

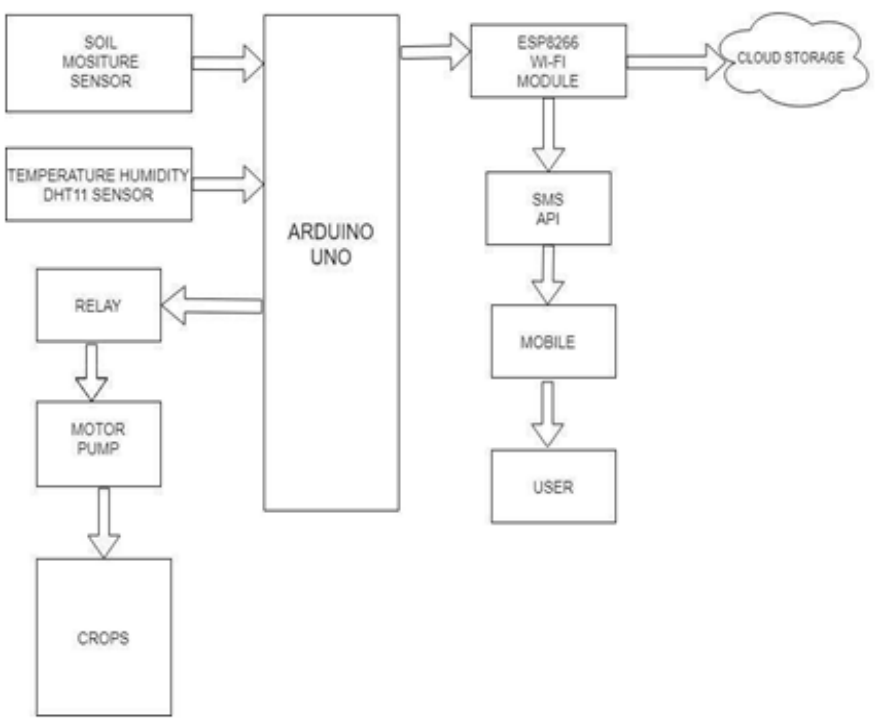

Fig 1:- Architecture of the proposed system

- When the power supply is ON, soil dampness sensor, temperature and mugginess sensor, water level detector startsto activate.

- Soil dampness sensors will detect the dampness of soil and through WSN the information will be moved to the actuators to continue as per that information.

- A limit esteem has been set and at whatever point the deliberate worth crosses the predefined edge esteem the engine gets turned on/off naturally. Same working goes with the water level sensor whenever the measured value of water level crosses the predefined threshold value the motor gets switched on/off automatically to fill the tank.

- Same working goes with the water level sensor at whatever point the deliberate estimation of water level crosses the predefined limit esteems the engine gets turned on/off consequently to fill the tank.

- A Wi-fi Module is associated with the microcontroller and all the sensors to show the status of dampness content in soil and water level in the tank.

- Readings data from the sensors are analyzed to check whether it is required to alert the user or continue monitoring.

\section{Flowchart:}

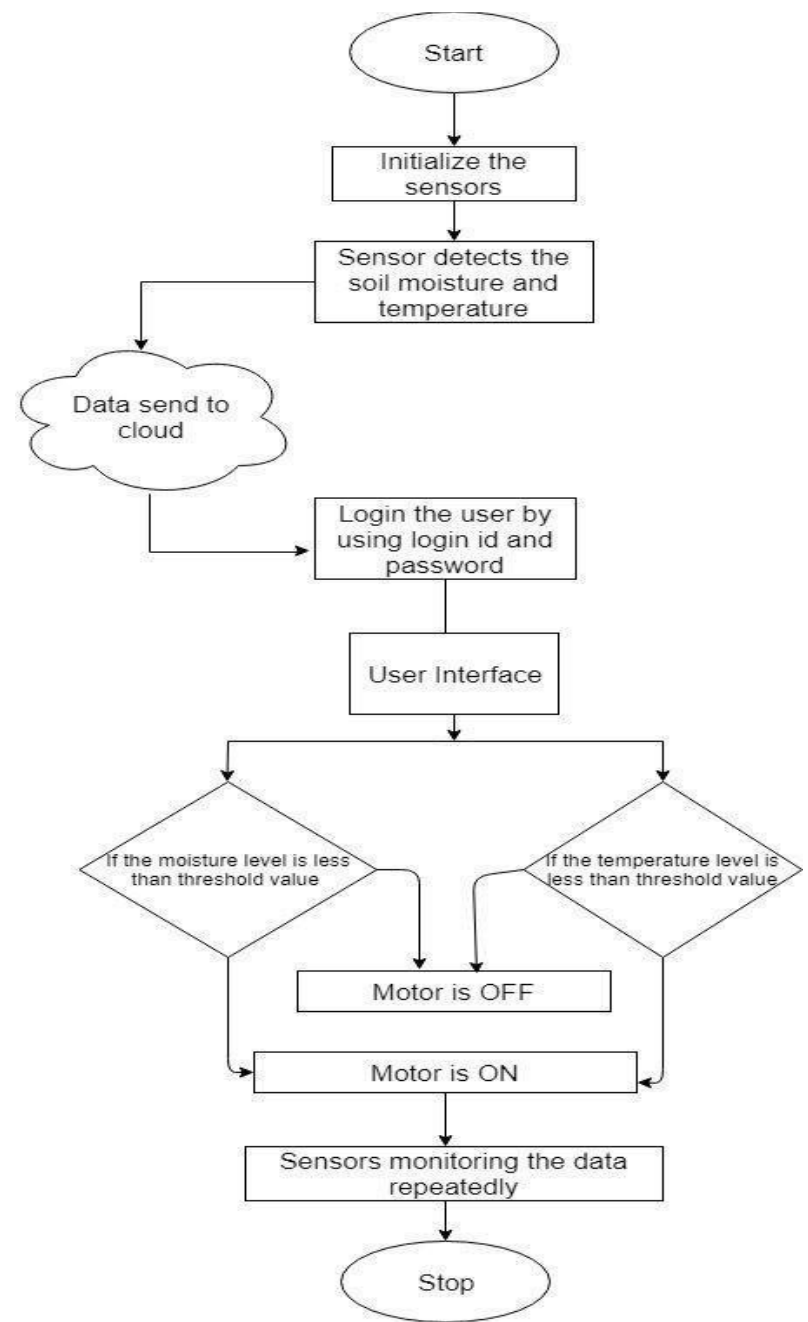

Fig 2:- Flowchart of the proposed system

IV. RESULT

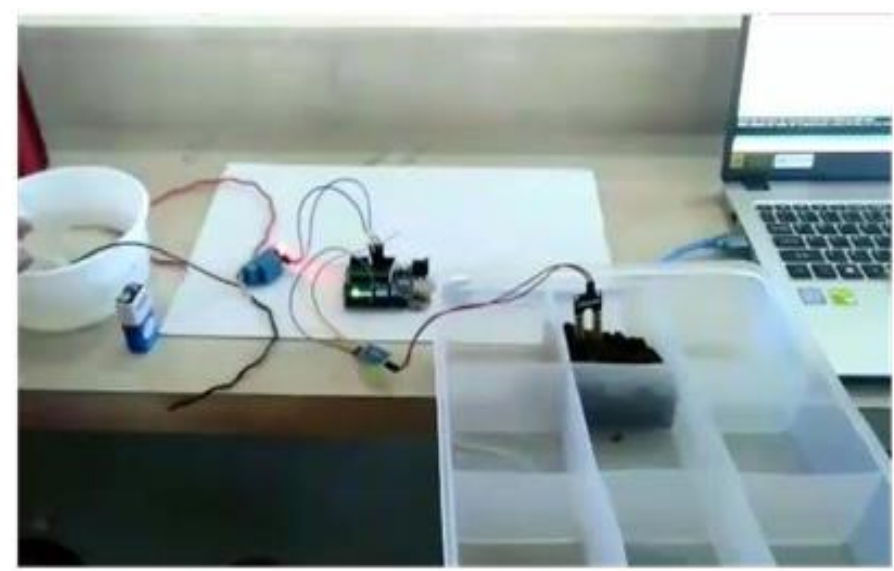

Fig 3:- Model Setup of the Proposed System 
This system is microcontroller based and website using the concept of cloud and data collection is used to record and control the water management system from remote location. Whole system is in WSN infrastructure. Website provide easy monitor and control mechanism to farmer. Graph generated in webpage makes it easy to analyse the data. In this system, sensors sense the data and send the reading to the microcontroller. Then the microcontroller sends those readings to the database that is connected to pc. These readings will be displayed on the webpage on real-time basis. The database is stored in the cloud, hence user can view database anytime anywhere with the help of internet.

\section{Implementation:}

\section{() (i) myirrigationsystem.online}

(2) :

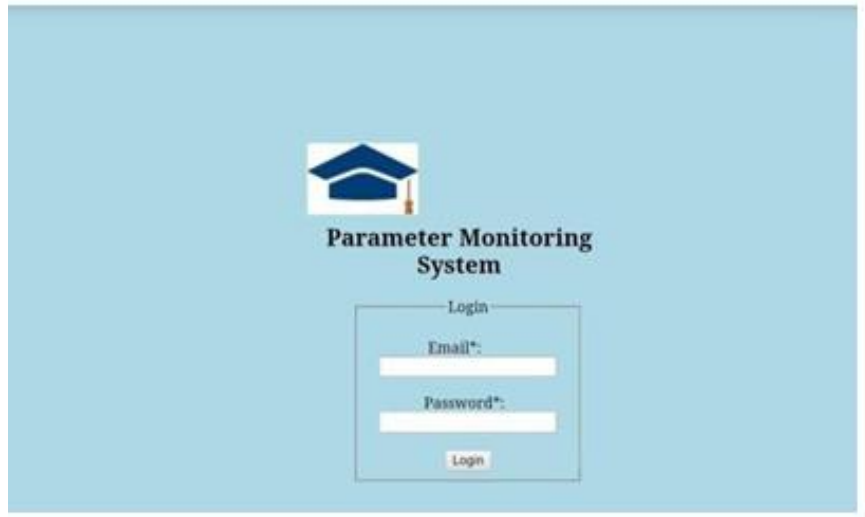

Fig 4:- Login page screen

\section{$\triangle \quad$ (i) myirrigationsystem.online/r (2) :}

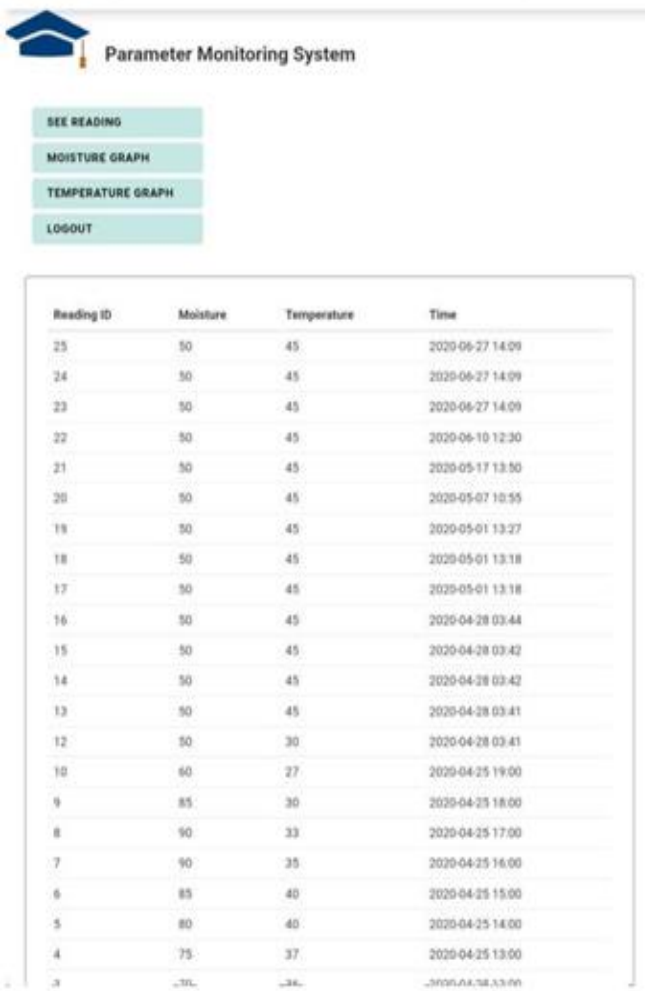

Fig 5:- A webpage screen showing real-time sensed data
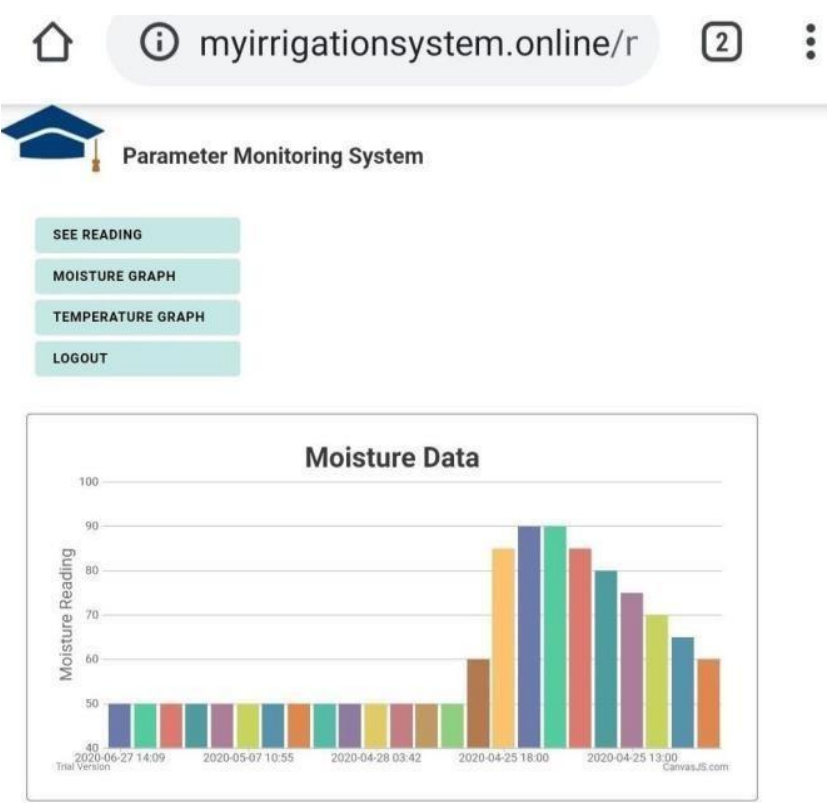

Fig 6:- Graphical representation of soil moisture level

\section{๑ (i) myirrigationsystem.online/t (2): Parameter Monitoring System}
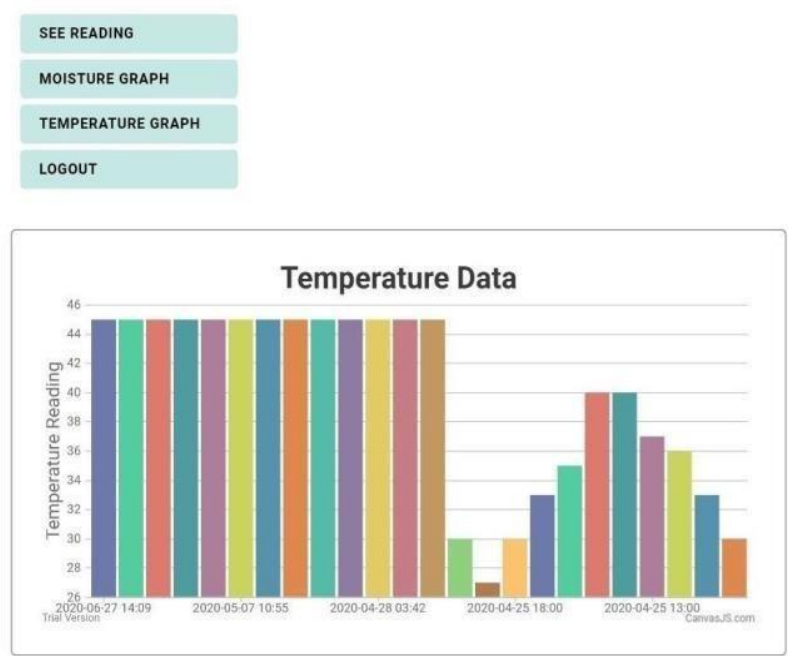

Fig 7:- Graphical representation of temperature reading

\section{APPLICATIONS}

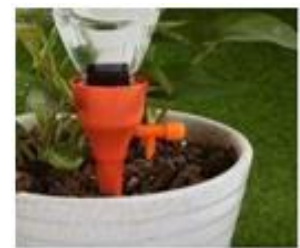

Gardening

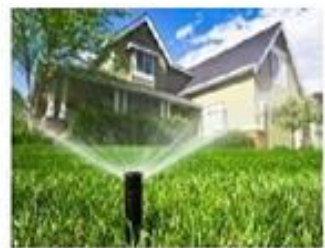

Lawns

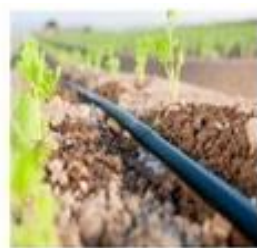

Agriculture

Fig 8:- Proposed system application 


\section{CONCLUSION}

This proposed system helps to improve productivity and reduces water consumption. It irrigates regularly according to needs, without much human intervention. It is possible to save half of water consumption compared to while manual watering. It is also helpful in the region where there is scarcity of water and improves their sustainability

As per future perspective, this system can be developed into a suitable system for large-scale creation and furthermore for a wide assortment of harvests having a place with various tropical areas.

An android application can also be built to provide a more personalized experience of the user.

Using Machine Learning algorithms, this system can be developed into a more intelligent system which can predict user actions, nutrient level of the plants, time to harvest, etc which will help farmers a lot.

\section{REFERENCES}

[1]. Arun.M, Abisha sugirtharani.J, Jenifer mercy carolina.P, Angel teresa.C Electronics and Communication Engineering

Panimalar Instiute Of Technology (Anna university), Chennai, India)

[2]. Vaishali, S., Suraj, S., Vignesh, G., Dhivya, S., \& Udhayakumar, S. (2017). Mobile integrated smart irrigation management and monitoring system using IOT. 2017 International Conference on Communication and SignalProcessing(ICCSP). doi:10.1109/iccsp.2017.82867 92 I.S. Jacobs and C.P. Bean, "Fine particles, thin films and exchange anisotropy," in Magnetism, vol. III, G.T. Rado and H. Suhl, Eds. New York: Academic, 1963, pp. 271-350.

[3]. Ghosh, S., Sayyed, S., Wani, K., Mhatre, M., \& Hingoliwala, H. A. (2016). Smart irrigation: A smart drip irrigation system using cloud, android and data mining. 2016 IEEE International Conference on Advances in Electronics, Communication and Computer Technology (ICAECCT). doi:10.1109/icaecct.2016.7942589 R.Nicole, "Title of paper with only first word capitalized," J. Name Stand. Abbrev., in press.

[4]. Thakare, S., \& Bhagat, P. H. (2018). Arduino-Based Smart Irrigation Using Sensors and ESP8266 WiFi Module. 2018 Second International Conference on Intelligent Computing and Control Systems (ICICCS).J. Clerk Maxwell, A Treatise on Electricity and Magnetism, 3rd ed., vol. 2. Oxford: Clarendon, 1892, pp.68-73.

[5]. Math, A., Ali, L., \& Pruthviraj, U. (2018). Development of Smart Drip Irrigation System Using IoT. 2018 IEEE Distributed Computing, VLSI, Electrical Circuits and Robotics (DISCOVER).
[6]. "SMART IRRIGATION SYSTEM". [Online]. Available: https://acadpubl.eu/hub/2018-11915/4/724.pdf [2] Yunseop Kim, Robert G. Evans, and William M. Iversen, "Remote Sensing and Control of an Irrigation System Using a Distributed Wireless Sensor Network" , IEEE, 2008.

[7]. Manish Giri, Dnyaneshwar Natha Wavhal .Automated Intelligent Wireless Drip Irrigation Using Linear Programming. International Journal of Advanced Research in Computer Engineering \& Technology (IJARCET)Volume 2, Issue 1(2013).

[8]. Miranda FR, Yoder RE, Wilkerson JB, Odhiamboc LO (2005). An autonomous controller for site-specific management of fixed irrigation systems.Comput.Electron. Agric., 48:183-197.

[9]. Joaquín Gutiérrez, Juan Francisco Villa-Medina, Alejandra Nieto-Garibay, and Miguel ÁngelPortaGándara, "Automated Irrigation System Using a Wireless Sensor Network and GPRS Module," IEEE Transactions on Instrumentation and Measurement, vol. 63, no. 1, January 2014.

[10]. Jia Uddin, S.M. Taslim Reza, Qader Newaz, Jamal Uddin, Touhidul Islam, and Jong-MyonKim, "Automated Irrigation System Using Solar Power" 2012 7th International Conference on Electrical and Computer Engineering. 